\title{
PENGARUH KUALITAS PELAYANAN TERHADAP KEPUASAN DAN LOYALITAS PASIEN PADA INSTALASI RAWAT INAP DI RSUD INDRASARI RENGAT
}

\author{
Desi Wardiati ${ }^{1}$, Zulkarnain ${ }^{2}$, Any Widiyatsari ${ }^{3}$ \\ ${ }^{1)}$ Mahasiswa Program Pascasarjana Universitas Riau \\ ${ }^{2), 3)}$ Dosen Program Pascasarjana Universitas Riau \\ Email : dessywardiati94@gmail.com ${ }^{1}$
}

\begin{abstract}
The study was conducted at Indrasari Rengat Inhu Hospital. The aim is to determine the direct effect of the dimensions of service quality, namely Tangible, Emphaty, Reliability, Responseveness, Assurance on patient satisfaction and loyalty. This study took a sample of 100 patients. The variables used are Tangible, Emphaty, Reliability, Responseveness, Assurance of patient satisfaction and loyalty. Data were analyzed using SEM (Structural Equation Modeling) analysis which is operated through the Smart PLS 3.2.7 program
\end{abstract}

The results showed that there was an effect of Tangible, Emphaty, Reliability, Responseveness, Assurance on patient satisfaction. And there is the influence of Tangible, Emphaty, Reliability, Responseveness, Assurance on patient loyalty through patient satisfaction and there is an influence between patient satisfaction variables on patient loyalty, the better the patient satisfaction will increase patient loyalty.

Keywords: service quality, patient satisfaction and patient loyalty

\section{Latar Belakang Masalah}

Masalah kesehatan bagi masyarakat telah menjadi suatu kebutuhan yang utama. Kebutuhan yang dimaksud adalah untuk mendapatkan pelayanan kesehatan .Seiring dengan keadaan sosial masyarakat yang semakin meningkat, dimana masyarakat semakin sadar kualitas atau mutu pelayanan kesehatan yang lebih berorientasi pada kepuasan konsumen.Artinya berupaya untuk memberikan pelayanan yang terbaik dan mengevaluasi berdasarkan sudut pandang konsumen.

Salah satu lembaga kesehatan yang menangani masyarakat adalah rumah sakit.Fungsi rumah sakit sekarang ini bertambah ke arah pelayanan kesehatan yang menyeluruh.Fungsi ini meliputi upaya penyembuhan bagi pelanggan yang sakit maupun yang membutuhkan konsultasi kesehatan dan upaya pencapaian serta peningkatan kesehatan.Untuk itu, rumah sakit dituntut untuk selalu menjaga kepercayaan dengan meningkatkan kualitas pelayanan agar kepuasan pelanggan meningkat. RSUD Indrasari Rengat merupakan rumah sakit pemerintah Tipe $\mathrm{C}$ yang berada dalam wilayah Pemerintah Daerah Indragiri Hulu Provinsi Riau yang diresmikan pada tanggal 26 Februari 1993.RSUD Indrasari Rengat Memiliki tempat tidur rawat inap sebanyak 154 dan terbagi 4 kelas, RSUD Indrasari Rengat memiliki ruangan rawatan kelas VIP dan ruangan khusus bayi baru lahir. ICU merupakan ruang an pelayanan insentif untuk dewasa yang memerlukan perawatan khusus. 
Tabel 1.1 Rekapitulasi Jumlah Pasien RSUD Indrasari Rengat, Tahun 2015 Sampai dengan Tahun 2018

\begin{tabular}{|l|l|l|c|}
\hline \multirow{2}{*}{ NO } & \multirow{2}{*}{ TAHUN } & \multicolumn{2}{|c|}{ JUMLAH PASIEN } \\
\cline { 3 - 4 } & & $\begin{array}{c}\text { RAWAT } \\
\text { INAP }\end{array}$ & $\begin{array}{c}\text { RAWAT } \\
\text { JALAN }\end{array}$ \\
\hline 1 & 2015 & 10.233 & 28.633 \\
\hline 2 & 2016 & 10.857 & 31.434 \\
\hline 3 & 2017 & 11.249 & 45.716 \\
\hline 4 & 2018 & 13.674 & 50.574 \\
\hline \multicolumn{4}{|c}{$\begin{array}{l}\text { Sumber : } \\
\text { Indrasari Rengat Rekam Medis } \text { RSUD }\end{array}$}
\end{tabular}

\section{TELAAH PUSTAKA}

\section{Loyalitas Pelanggan}

Setiap perusahaan selalu berusaha memberikan layanan yang terbaik bagi konsumen, pelayanan yang baik akan berdampak terdadap loyalitas konsumen. Menurut Gaffar (2007:70) menyatakan bahwa loyalitas konsumen adalah komitmen untuk bertahan secara mendalam untuk melakukan pembelian ulang atau berlangganan kembali secara konsisten di masa yang akan datang, meskipun pengaruh situasi dan usaha pemasaran mempunyai potensi untuk menyebabkan perubahan terhadap perilaku. Menurut Jeon (2017:444), Loyalty didefinisikan sebagai sikap konsumen yang menguntungkan penjual, yang menghasilkan pembelian ulang loyalitas merupakan dampak dari kepuasan konsumen terhadap kualitas pelayanan. Memiliki pelanggan yang loyal sangat menguntungkan bagi perusahan, mengingat persaingan yang tinggi pada industri rumah sakit, konsumen yang loyal akan merekomendasikan kepada teman maupun keluarga mereka untuk ikut melakukan pembelian.

\section{Kepuasan Pelanggan}

Kepuasan Pelanggan Di dalam suatu proses keputusan, konsumen tidak akan berhenti hanya sampai proses penggunaan. Konsumen akan melakukan proses evaluasi terhadap penggunaan yang telah dilakukannya. Inilah yang disebut dengan evaluasi alternatif pasca pembelian atau pasca penggunaan. Proses ini juga dapat disebut sebagai proses evaluasi alternatif tahap kedua. Hasil dari evaluasi pasca penggunaan tahap kedua adalah konsumen puas atau tidak puas terhadap perusahaan yang telah dilakukannya. Setelah menggunakan, konsumen akan memiliki perasaan puas atau tidak puas terhadap perusahaan. Kepuasan akan mendorong konsumen membeli dan mengggunakan ulang produk tersebut. Sebaliknya perasaan yang tidak puas akan menyebabkan konsumen kecewa dan menghentikan pembelian kembali dan penggunakan perusahaan tersebut (Sumarwan, 2014:321).

\section{Kualitas Pelayanan}

\section{Pelayanan}

merupakan

komponen penting yang harus diperhatikan dalam pelayanan. Istilah kualitas pelayanan tentunya tidak dapat dipisahkan dari persepsi tentang kualitas. Beberapa pengertian kualitas menurut Hardiyansyah (2011:40) adalah:

(1)Kesesuaian dengan persyaratan; (2) Kecocokan untuk pemakaian; (3) Perbaikan Bekelanjutan; (4) Bebas dari kerusakan/cacat; (5) Pemenuhan kebutuhan pelanggan sejak awal dan setiap saat; (6) Melakukan segala sesuatu secara benar; (7) sesuatu yang bisa membahagiakan pelanggan. 
PENGARUH KUALITAS PELAYANAN TERHADAP KEPUASAN DAN LOYALITAS PASIEN PADA INSTALASI RAWAT INAP DI RSUD INDRASARI RENGAT

\section{METODE PENELITIAN}

\section{Lokasi Penelitian}

Penelitian ini dilakukan pada RSUD Indrasari Rengat yang beralamat di JL. Raya Lintas Timur Pematang Reba, Inhu Riau Telp. 0769341061

\section{Metode Penelitian}

Jenis penelitian yang digunakan dalam penelitian ini adalah metode deskriptif dan metode asosiatif dengan menanyakan hubungan kasual (sebab-akibat).

\section{Populasi dan sampel}

Populasi dalam penelitian ini adalah seluruh pelanggan yang melakukan Perawatan pada RSUD Indrasari Rengat pada Tahun 2018 yang berjumlah sebanyak 6.482 orang. Dan sampel sebanyak 100 orang

\section{Hasil dan pembahasan}

Pengujian hipotesis menggunakan Partial Least Square (PLS) akan memperlihatkan sebelas hipotesis. Pengujian ini dilakukan dengan menggunakan uji $\mathrm{t}$ (t-test) pengaruh antara variabel.

\begin{tabular}{|c|c|c|c|}
\hline No & Pengaruh & $\begin{array}{c}\mathbf{P} \\
\text { Values }\end{array}$ & Ket \\
\hline 1 & $\begin{array}{l}\text { Tangible } \rightarrow \\
\text { Kepuasan } \\
\text { Pelanggan }\end{array}$ & 0,029 & Signifikan \\
\hline 2 & $\begin{array}{l}\text { Empathy } \rightarrow \\
\text { Kepuasan } \\
\text { Pelanggan }\end{array}$ & 0,016 & Signifikan \\
\hline 3 & $\begin{array}{l}\text { Realibility } \rightarrow \\
\text { Kepuasan } \\
\text { Pelanggan }\end{array}$ & 0,029 & Signifikan \\
\hline 4 & $\begin{array}{l}\text { Responsiveness } \\
\rightarrow \text { Kepuasan } \\
\text { Pelanggan }\end{array}$ & 0,005 & Signifikan \\
\hline 5 & $\begin{array}{l}\text { Assurance } \rightarrow \\
\text { Kepuasan } \\
\text { Pelanggan }\end{array}$ & 0,001 & Signifikan \\
\hline 6 & $\begin{array}{l}\text { Tangible } \rightarrow \\
\text { Kepuasan } \\
\text { Pelanggan } \rightarrow \\
\text { Loyalitas }\end{array}$ & 0,024 & Signifikan \\
\hline 7 & $\begin{array}{l}\text { Empathy } \rightarrow \\
\text { Kepuasan } \\
\text { Pelanggan } \rightarrow \\
\text { Loyalitas }\end{array}$ & 0,013 & Signifikan \\
\hline 8 & $\begin{array}{l}\text { Realibility } \rightarrow \\
\text { Kepuasan } \\
\text { Pelanggan } \rightarrow \\
\text { Loyalitas }\end{array}$ & 0,024 & Signifikan \\
\hline 9 & $\begin{array}{l}\text { Responsiveness } \\
\rightarrow \text { Kepuasan } \\
\text { Pelanggan } \rightarrow \\
\text { Loyalitas }\end{array}$ & 0,003 & Signifikan \\
\hline 10 & $\begin{array}{l}\text { Assurance } \rightarrow \\
\text { Kepuasan } \\
\text { Pelanggan } \rightarrow \\
\text { Loyalitas }\end{array}$ & 0,001 & Signifikan \\
\hline 11 & $\begin{array}{l}\text { Kepuasan } \\
\text { Pelanggan } \rightarrow \\
\text { Loyalitas }\end{array}$ & 0,001 & Signifikan \\
\hline
\end{tabular}

1. Tangible $\rightarrow$ Kepuasan Pelanggan Diperoleh nilai $\mathrm{P}$ value sebesar 0,029. Hasil tersebut menunjukkan bahwa $\mathrm{p}$ value $(0,029)$ lebih kecil dari 0,05 . Artinya adalah bahwa tangible berpengaruh terhadap kepuasan 
pelanggan. Diperoleh nilai path keofisien sebesar 0,182 yang berarti bahwa setiap peningkatan tangible sebesar 1 satuan maka akan meningkatkan kepuasan pelanggan sebesar 0,182 dan sebaliknya dengan asumsi variabel lain konstan.

2. Empathy $\rightarrow$ Kepuasan Pelanggan Diperoleh nilai $\mathrm{P}$ value sebesar 0,016. Hasil tersebut menunjukkan bahwa $\mathrm{p}$ value $(0,016)$ lebih kecil dari 0,05 . Artinya adalah bahwa empathy berpengaruh terhadap kepuasan pelanggan. Diperoleh nilai path keofisien sebesar 0,205 yang berarti bahwa setiap peningkatan empathy sebesar 1 satuan maka akan meningkatkan kepuasan pelanggan sebesar 0,205 dan sebaliknya dengan asumsi variabel lain konstan.

3. Realibility $\rightarrow$ Kepuasan Pelanggan

Diperoleh nilai $\mathrm{P}$ value sebesar 0,029. Hasil tersebut menunjukkan bahwa $\mathrm{p}$ value $(0,029)$ lebih kecil dari 0,05 . Artinya adalah bahwa realibility berpengaruh terhadap kepuasan pelanggan. Diperoleh nilai path keofisien sebesar 0,182 yang berarti bahwa setiap peningkatan realibility sebesar 1 satuan maka akan meningkatkan kepuasan pelanggan sebesar 0,182 dan sebaliknya dengan asumsi variabel lain konstan.

4. Responsiveness $\rightarrow$ Kepuasan Pelanggan

Diperoleh nilai $\mathrm{P}$ value sebesar 0,005. Hasil tersebut menunjukkan bahwa $\mathrm{p}$ value $(0,005)$ lebih kecil dari 0,05 . Artinya adalah bahwa responsiveness berpengaruh terhadap kepuasan pelanggan.
Diperoleh nilai path keofisien sebesar 0,248 yang berarti bahwa setiap peningkatan responsiveness sebesar 1 satuan maka akan meningkatkan kepuasan pelanggan sebesar 0,248 dan sebaliknya dengan asumsi variabel lain konstan.

5. Assurance $\rightarrow$ Kepuasan Pelanggan

Diperoleh nilai $\mathrm{P}$ value sebesar 0,001. Hasil tersebut menunjukkan bahwa $\mathrm{p}$ value $(0,001)$ lebih kecil dari 0,05 . Artinya adalah bahwa assurance berpengaruh terhadap kepuasan pelanggan. Diperoleh nilai path keofisien sebesar 0,290 yang berarti bahwa setiap peningkatan assurance sebesar 1 satuan maka akan meningkatkan kepuasan pelanggan sebesar 0,290 dan sebaliknya dengan asumsi variabel lain konstan.

6. Tangible $\rightarrow$ Kepuasan Pelanggan $\rightarrow$ Loyalitas Pelanggan

Diperoleh nilai $\mathrm{P}$ value sebesar 0,024. Hasil tersebut menunjukkan bahwa $\mathrm{p}$ value $(0,024)$ lebih kecil dari 0,05 . Artinya adalah bahwa tangible berpengaruh terhadap loyalitas pelanggan melalui kepuasan pelanggan. Diperoleh nilai path keofisien sebesar 0,136 yang berarti bahwa setiap peningkatan tangible melalui kepuasan pelanggan sebesar 1 satuan maka akan meningkatkan loyalitas pelanggan sebesar 0,136 dan sebaliknya dengan asumsi variabel lain konstan.

7. Empathy $\rightarrow$ Kepuasan Pelanggan $\rightarrow$ Loyalitas Pelanggan

Diperoleh nilai $\mathrm{P}$ value sebesar 0,013. Hasil tersebut menunjukkan bahwa $\mathrm{p}$ value $(0,013)$ lebih kecil dari 0,05 . 
Artinya adalah bahwa empathy berpengaruh terhadap loyalitas pelanggan melalui kepuasan pelanggan. Diperoleh nilai path keofisien sebesar 0,153 yang berarti bahwa setiap peningkatan empathy melalui kepuasan pelanggan sebesar 1 satuan maka akan meningkatkan loyalitas pelanggan sebesar 0,153 dan sebaliknya dengan asumsi variabel lain konstan.

8. Realibility $\rightarrow$ Kepuasan Pelanggan $\rightarrow \quad$ Loyalitas Pelanggan

Diperoleh nilai $\mathrm{P}$ value sebesar 0,024. Hasil tersebut menunjukkan bahwa $\mathrm{p}$ value $(0,024)$ lebih kecil dari 0,05 . Artinya adalah bahwa realibility berpengaruh terhadap loyalitas pelanggan melalui kepuasan pelanggan. Diperoleh nilai path keofisien sebesar 0,136 yang berarti bahwa setiap peningkatan realibility melalui kepuasan pelanggan sebesar 1 satuan maka akan meningkatkan loyalitas pelanggan sebesar 0,136 dan sebaliknya dengan asumsi variabel lain konstan.

9. Responsiveness $\rightarrow$ Kepuasan Pelanggan $\rightarrow \quad$ Loyalitas Pelanggan

Diperoleh nilai $\mathrm{P}$ value sebesar 0,003. Hasil tersebut menunjukkan bahwa $\mathrm{p}$ value $(0,003)$ lebih kecil dari 0,05 . Artinya adalah bahwa responsiveness berpengaruh terhadap loyalitas pelanggan melalui kepuasan pelanggan. Diperoleh nilai path keofisien sebesar 0,185 yang berarti bahwa setiap peningkatan responsiveness melalui kepuasan pelanggan sebesar 1 satuan maka akan meningkatkan loyalitas pelanggan sebesar 0,185 dan

sebaliknya dengan asumsi variabel lain konstan.

10. Assurance $\rightarrow$ Kepuasan

Pelanggan $\rightarrow \quad$ Loyalitas

Pelanggan

Diperoleh nilai $\mathrm{P}$ value sebesar $<0,001$. Hasil tersebut menunjukkan bahwa $\mathrm{p}$ value $(<0,001)$ lebih kecil dari 0,05 . Artinya adalah bahwa assurance berpengaruh terhadap loyalitas pelanggan melalui kepuasan pelanggan. Diperoleh nilai path keofisien sebesar 0,217 yang berarti bahwa setiap peningkatan assurance melalui kepuasan pelanggan sebesar 1 satuan maka akan meningkatkan loyalitas pelanggan sebesar 0,217 dan sebaliknya dengan asumsi variabel lain konstan.

11. Kepuasan Pelanggan $\rightarrow$ Loyalitas Pelanggan

Diperoleh nilai $\mathrm{P}$ value sebesar $<0,001$. Hasil tersebut menunjukkan bahwa $\mathrm{p}$ value $(<0,001)$ lebih kecil dari 0,05 . Artinya adalah bahwa kepuasan pelanggan berpengaruh terhadap loyalitas pelanggan. Diperoleh nilai path keofisien sebesar 0,747 yang berarti bahwa setiap peningkatan kepuasan pelanggan sebesar 1 satuan maka akan meningkatkan loyalitas pelanggan sebesar 0,747 dan sebaliknya dengan asumsi variabel lain konstan

\section{Kesimpulan dan saran}

Dari hasil penelitian yang telah dipaparkan pada BAB sebelumnya, maka dapat ditarik kesimpulan penelitian ini sebagai berikut:

1. Terdapat pengaruh tangible terhadap kepuasan pelanggan 
pada RSUD Indrasari Rengat Inhu. Semakin baik tangible maka kepuasan pelanggan akan semakin meningkat dan sebaliknya, semakin kurang baik tangible maka kepuasan pelanggan akan semakin menurun.

2. Terdapat pengaruh emphaty terhadap kepuasan pelanggan pada RSUD Indrasari Rengat Inhu. Semakin baik emphaty maka kepuasan pelanggan akan semakin meningkat dan sebaliknya, semakin kurang baik emphaty maka kepuasan pelanggan akan semakin menurun.

3. Terdapat pengaruh reliability terhadap kepuasan pelanggan pada RSUD Indrasari Rengat Inhu. Semakin baik reliability maka kepuasan pelanggan akan semakin meningkat dan sebaliknya, semakin kurang baik reliability maka kepuasan pelanggan akan semakin menurun.

4. Terdapat pengaruh responsiveness terhadap kepuasan pelanggan pada RSUD Indrasari Rengat Inhu. Semakin baik responsiveness maka kepuasan pelanggan akan semakin meningkat dan sebaliknya, semakin kurang baik responsiveness maka kepuasan pelanggan akan semakin menurun.

5. Terdapat pengaruh assurance terhadap kepuasan pelanggan pada RSUD Indrasari Rengat Inhu. Semakin baik assurance maka kepuasan pelanggan akan semakin meningkat dan sebaliknya, semakin kurang baik assurance maka kepuasan pelanggan akan semakin menurun.

6. Terdapat pengaruh tangible terhadap Loyalitas pelanggan melalui Kepuasan Pelanngan pada RSUD Indrasari Rengat Inhu. Semakin baik tangible maka Loyalitas pelanggan akan semakin meningkat dan sebaliknya, semakin kurang baik tangible maka Loyalitas pelanggan akan semakin menurun.

7. Terdapat pengaruh emphaty terhadap Loyalitas pelanggan melalui Kepuasan Pelanngan pada RSUD Indrasari Rengat Inhu. Semakin baik emphaty maka Loyalitas pelanggan akan semakin meningkat dan sebaliknya, semakin kurang baik emphaty maka Loyalitas pelanggan akan semakin menurun.

8. Terdapat pengaruh reliability terhadap Loyalitas pelanggan melalui Kepuasan Pelanggan pada RSUD Indrasari Rengat Inhu. Semakin baik reliability maka Loyalitas pelanggan akan semakin meningkat dan sebaliknya, semakin kurang baik reliability maka Loyalitas pelanggan akan semakin menurun.

9. Terdapat pengaruh responsiveness terhadap Loyalitas pelanggan melalui Kepuasan Pelanggan pada RSUD Indrasari Rengat Inhu. Semakin baik responsiveness maka Loyalitas pelanggan akan semakin meningkat dan sebaliknya, semakin kurang baik responsiveness maka Loyalitas pelanggan akan semakin menurun. 
10. Terdapat pengaruh assurance terhadap Loyalitas pelanggan melalui Kepuasan Pelanggan pada RSUD Indrasari Rengat Inhu. Semakin baik assurance maka Loyalitas pelanggan akan semakin meningkat dan sebaliknya, semakin kurang baik assurance maka Loyalitas pelanggan akan semakin menurun, namun pengaruhnya tidak signifikan.

11. Terdapat pengaruh kepuasan Pelanggan terhadap Loyalitas pelanggan pada RSUD Indrasari Rengat Inhu. Semakin tinggi kepuasan pelanggan maka loyalitas pelanggan akan semakin meningkat dan sebaliknya, semakin rendah kepuasan pelanggan maka loyalitas pelanggan akan semakin menurun.

\section{Saran}

Dari hasil penelitian dan kesimpulan yang sudah dijelaskan sebelumnya, maka penulis memberikan saran sebagai berikut:

1. Hasil penelitian menunjukkan bahwa tanggapan pasien terhadap kualitas pelayanan pada RSUD Indrasari Rengat sudah baik. Walaupun demikian, RSUD Indrasari Rengat dinilai sangat perlu untuk meningkatkan lagi kualitas pelayanan kepada pasien mengingat semakin hari tingkat persaingan bisnis yang serupa semakin meningkat. Jika hal ini tidak dilakukan maka besar kemungkinan pasien akan berpindah ke rumah sakit atau klinik pengobatan lainnya.
2. Tingginya persaingan bisnis kesehatan di Indragiri Hulu membuat para pasien berpupaya untuk mencari pelayanan kesehatan lain yang mampu memberikan biaya pengobatan yang murah tanpa mengurangi kualitas. Untuk itu RSUD Indrasari Rengat perlu untuk mempertimbangkan faktor biaya pelayanan jasa dan selalu mengevaluasi biaya agar mampu bersaing dengan pesaing lainnya.

3. RSUD Indrasari Rengat seharusnya menyediakan ruang diskusi untuk mencari tahu detail informasi tentang pelayanan. Untuk itu diperlukannya semacam media komunikasi pada RSUD Indrasari Rengat yang berisikan informasi lengkap tentang pelayanan, sehingga pasien tidak susah payah untuk mencari tahu informasi pelayanan yang disediakan. Selain itu ruang diskusi juga diperlukan untuk sharing pengalaman antar pasien yang tersebar diseluruh $\mathrm{Kab}$ Indragiri Hulu, dengan demikian pasien dapat mendapatkan kepuasan informasi tentang langkah perawatan apa yang akan diambil oleh pasien.

4. Dengan melakukan beberapa peningkatan yang telah dipaparkan, diharapkan kepuasan pelanggan RSUD Indrasari Rengat lebih meningkat sehingga loyalitas pelanggan juga semakin bertambah. pasien yang loyal akan melakukan perawatan yang berkala dan mengajak 
orang lain untuk ikut berobat ke RSUD Indrasari Rengat. Dengan demikian, RSUD akan mendapatkan pasien baru dan tentunya omset akan meningkat.

5. Diharapkan kepada peneliti selanjutnya untuk menggunakan metode wawancara serta angket terbuka dalam penelitian, agar data yang diperoleh sesuai dengan keadaan yang sebenarnya. Disamping itu juga perlu menambahkan variabel lain yang mempengaruhi kepuasan dan loyalitas Pasien RSUD Indrasari REngat berdasarkan karakteristik serta alat analisis lain.

\section{Daftar Pustaka}

Adisasmito,Wiku.2008. Kesiapan Rumah Sakit Dalam Menghadapi Globalisasi.

Jakarta : Fakultas Kesehatan Masyarakat Universitas Indonesia

Arikunto, Suharsimi.2006, Prosedur Penelitian Suatu Penelitian Suatu Pendekatan Praktek, Jakarta : PT. Rineka Cipta

Atalik, Ozlem. 2009. Pelanggan

Value Analysis from a Pelanggan's Perspective :Case of Turkish Airlines Domestic Passengers. Journal International Business Research. Vol.2, No.3, pp 8591

Brady, M. K., \& Cronin.2001. Some New Thought on Conceptualizing Perceived Service Quality : A Hierarchical Approach. The Journal of Marketing Vol.65,34-49
Aulia, Ferdy.2010. Analisis pengaruh kualitas pelayanan dan citra terhadap kepuasan pelanggan dan dampaknya terhadap loyalitas pelanggan pada Rumah Sakit Pusat Pertamina. Tesis. Universitas Bina Nusantara. http://eprints.binus.ac.id/id/id leprint/10140 Download : 29 Februari 2012

Aussauri, Sofjan. 2003. Pelanggan Service yang Baik Landasan Pencapaian Pelanggan Kepuasan, Usahawan. No 01. Tahun XXXII. Januari. Hal. 25-30. Jakarta.

Brady, M. K., \& Cronin.2001. Some New Thought on Conceptualizing Perceived Service Quality : A Hierarchical Approach. The Journal of Marketing Vol.65,34-49

Brajadenta, Gara Samar. 2012. Pengaruh persepsi pelanggan tentang dimensi kualitas pelayanan terhadap citra Rumah Sakit Umum Daerah Waled Kabupaten Cirebon : studi pada pelanggan rawat inap kelas I dan VIP. Tesis. Universitas Jenderal Soedirman.

http://mm.unsoed.ac.id.

Download : 29 Februari 2012

Cengiz, Emrah. 2010. Measuring Pelanggan Kepuasan : Must or Not? Journal of Naval Science and Engineering, Vol.6,pp.76-88

Damodar N Gujarati. 2011. DasarDasar Ekonometrik. Jakarta : Salemba Empat 
Elu, Balthasar. 2005. Manajemen Penanganan Komplain Konsumen Industri Jasa. Junal Ilmu Administrasi dan Organisasi, Bisnis \& Birokrasi, Vol. 13, No.3

Fonseca,Filipa et.Al.,2010. Service Quality and Pelanggan Kepuasan in Public Transports. Internasional Journal For Quality Research, Vol. 4, No.2,pp.125-130

Gasperz, Vincen.2005. Total Guality Management. Jakarta : PT Gramedia Pustaka Utama

Gunawan, Ketut dan Sundring Djati.2011.Kualitas Layanan dan Loyalitas Pelanggan (Studi pada Rumah Sakit Swasta di Kota SingarajaBali) Jurnal Manajemen dan
Kewirausahaan, Vol 13. No.1, Maret $2011: 32-39$

Mardikawati, Woro dan Farida, Naili.2013. Pengaruh Nilai Pelanggan dan Kualitas Layanan Terhadap Loyalitas Pelanggan, Melalui Kepuasan Pelanggan pada Pelanggan Bus Efisiensi. Jurnal Administrasi Bisnis, Vol.2,No.1,pp 64-75

Mosahab, et.al.,2010,Service Quality, Pelanggan Kepuasan and Loyalitas : A Test of Mediation, Journal Internasional Business Research, Vol.4,pp 72-80

Muninjay, A.A Gde.2012. Manajemen Mutu Pelayanan Kesehatan. Jakarta : Penerbit Buku Kedokteran EGC 